\title{
Virtual Face-to-Face Communication and the Learning Experience of Post-Graduate Students Studying via Flexible Delivery Mode
}

Kate Thomson, Boon-Kiang Tan and Christopher Brook

The Centre for International Health (CIH) at Curtin University of Technology delivers its postgraduate courses primarily via flexible delivery mode. This study aimed to determine the necessity, practicality and effectiveness of implementing virtual online face-to-face communication between students and their tutor. Two units were used as case exemplars for this study. Both units promoted virtual face-to-face communication through Skype or MSN during the teaching semester, in addition to email support. The tutor recorded her experience throughout the semester, including students' details, duration of contact and difficulties encountered. Students' experiences were assessed using an online survey, with a hyperlink sent to students' preferred email addresses. Demographic data were collated to allow for an investigation of their effect on student perception and uptake of services. The survey explored student perception of current services and communication, their experience of flexible delivery mode, and their uptake of and experience of virtual online face-to-face communication. Results indicated most students were satisied with email communication, but they believe additional support services and opportunities for communication would enhance their learning experience. The experience of those who communicated through Skype was generally positive, and they reported a higher level of engagement. There is support for further implementation, as the service would likely be utilised by a small proportion of students (those who feel isolated or are dissatisfied with email communication), which would create 
a manageable increase in the tutor's workload. For students located outside Australia, this provides a financially viable alternative to international telephone communication.

There are issues surrounding the economic sustainability of the current methodology used in the provision of traditional higher education, and the flexible mode of delivery has received interest from institutions as a more viable alternative (Bridgland \& Blanchard, 200I). Additionally, non-traditional modes of study that grant students control over their learning experience are attractive to the ever-diversifying student body (Elison-Bowers et al, 2008; Leach \& Walker, 2000). Although flexible delivery commonly appeals to international students and dispersed population, it is increasingly preferred by students who live close to their university campus, as it provides them the opportunity to learn at a time and place of their choice (Bridgland \& Blanchard, 200I). Research has found both similarities and differences between those who did and did not study through the flexible delivery mode; in terms of characteristics, levels of satisfaction and interaction, and learning experience (Elison-Bowers et al, 2008; Richardson \& Price, 2003). The literature recommends that universities look to future technologies, and the provision of various learning options, to ensure they do not disadvantage any group of students (Bonk \& King, 1998; Leach \& Walker, 2000).

\section{Higher Education and Flexible Delivery}

Higher Education has traditionally entailed hundreds of students sitting in a lecture hall for several hours each week, spending additional time at oncampus libraries and joining an array of student organisations. Today, this is supplemented with students who may never visit a university campus, but complete their entire program of study through flexible delivery and interact with their educators almost exclusively through Computer Mediated Communication (CMC) (Richardson \& Price, 2003). Computer Mediated Communication was originally designed to increase connectivity (Hiltz \& Turoff, 1985) and has grown to include synchronous chat and computer conference systems, email, newsgroups, support networks, bulletin boards and homepages (Khan, 2005), and more recently, social network sites such as 'MySpace' and 'Facebook' (Ellison, Steinfeld \& Lampe, 2007).

The flexible delivery of Higher Education is a changing paradigm and influenced by educators, students and technology (Muirhead \& Betz, 2005). Early examples of flexible delivery were in Europe (1856) and America (1873), where educators and students exchanged learning materials via post (McKenzie, Christensen \& Rigby, 1968; Simonson, Smaldino, Albright \& Zvacek, 2000). Flexible delivery has evolved to include a variety of modes, from those similar to the late igth century, to exclusively online learning. Taylor (1995; 2000) summarised some characteristics of flexible delivery that he believed affect the quality of teaching and learning. Flexibility of time, place and pace of learning characterised earlier models. Interactive de- 
livery was then prioritised over flexibility, and it was not until the flexible learning model that flexibility and interactive delivery were brought together (Taylor, I995; 2000). The model of flexible delivery offered in Higher Education today offers students a combination of internet-based access to online resources and CMC. Flexible delivery creates an opportunity for a change in the role of educators; from providers of information to facilitators of the learning experience (Berge, 2007; Nichols \& Gardner, 2002).

Key advantages of flexible delivery are student control over the time, pace and place of their learning (Bridgland \& Blanchard, 200I). While this is benficial, some of the issues associated with flexible delivery are the lack of organisational support at faculty and/or institutional level; requirements for additional resources and minimal or nonexistent face-to-face communication (Nichols \& Gardner, 2002). This study sought to explore the interaction between tutor and students facilitated by CMC and its influence on the teaching and learning experience.

\section{Higher Education Students}

Students' needs, their educator's style and institutional support, can impact on their learning experience (Bridgland \& Blanchard, 200I; Khan, 2005; Richardson \& Price, 2003). Institutions with a large number of students from lower socio-economic backgrounds and a highly diverse student population find it more challenging to enhance the learning experience (Yorke et al, 2005). An increasingly diverse student body may require universities to shift from an 'integration approach' (integrating students into a particular academic culture) toward a more learner-centred 'adaptation approach', where institutions adapt their administrative and academic cultures to meet the various learning patterns, abilities and interests of a heterogeneous student body (Zepke et al, 2005).

Research consistently shows that student characteristics such as gender, age, cultural background and academic ability, can significantly impact performance on measures relating to academic achievement (Yorke et al, 2005). Student characteristics influence the learning needs and uptake of services provided. For example, age has been shown to influence use of Web Course Tools (WebCT) and use of WebCT can affect performance (Hoskins \& van Hoof, 2005). Generally, female students have also been shown to have superior learning outcomes to male students (Yorke et al, 2005). Variables such as cultural background, previous educational experience and current circumstances affect the level of support and contact desired by students (Frank, Toland \& Schenk, 2004; Simpson, 200o) and educators should provide appropriate support for all students (Hiltz \& Johnson, I990; Smith \& Smith, I999).

The literature recommends research into developing online environments that not only enhance learning outcomes, but also appeal to a diverse student population (Leach \& Walker, 2000). Kember (2007) argues for further research; in particular, explorations of combining online courses 
with face-to-face communication to enhance students' learning experience. There is support for systems that emphasise pedagogy over technology (Bonk \& King, I998; Bridgland \& Blanchard, 200I) as technological enhancements do not automatically transfer to improvements in students' learning experience (Kember, 2007). As many students, particularly those studying through flexible delivery mode, may have time, financial and personal constraints limiting their ability to adapt to change; new technologies imposed should contribute to positive outcomes rather than additional challenges (Elison-Bowers et al, 2008). Thus, it is imperative that support strategies be trialled prior to implementation to determine their practicality and feasibility, particularly from the student perspective (Nichols \& Gardner, 2002).

\section{The current study}

The Centre for International Health (CIH) at Curtin University of Technology has been recognised for demonstrating a consistently outstanding performance in teaching and learning. Student feedback, in addition to other measures, indicated that they exhibit best practice in flexible delivery. According to figures from the 2007 Curtin Annual Student Satisfaction Survey, students studying through flexible delivery mode are satisfied with services overall (CASS, 2008). The current study gave students the opportunity to provide $\mathrm{CIH}$ with recommendations for improvements to existing services or additional services, such as CMC tools. For CIH staff to continue to meet the needs of students and exhibit best practice in flexible delivery, it is important they support innovative measures such as CMC.

As CIH caters primarily to those studying through flexible delivery mode, they should be aware of students' perceptions of current support in order to determine future initiatives. The current atmosphere in the Higher Education sector, technological developments, and the advancement of $\mathrm{CIH}$ are substantial drivers for research like this. This research sought to determine the necessity, practicality and effectiveness of implementing virtual online face-to-face communication between individual postgraduate students and their tutor. The authors were also interested in students' uptake, perceptions, and experience of this mode of communication; particularly in terms of their learning experience. This study has the potential to inform the application of CMC in Higher Education and enhance the teaching and learning experience of educators and students.

\section{Method}

This study was conducted over a I4-week semester from July to November 2008. The sample chosen for participation were students enrolled in two units offered via flexible delivery mode by CIH. These two units were selected as they generally have reasonable enrolment rates. Although this was 
not a large sample, virtual online face-to-face communication requires investigation before broad implementation, as it may not be practical or desirable for students or educators. Therefore, this sample was considered sufficient for an exemplar case study.

In the first week of semester, the tutor emailed students to promote $\mathrm{CMC}$ as an alternative mode of communication. Students were asked to organise a mutually convenient date and time with the tutor before they attempted to 'chat' via Skype or MSN. A one-page summary of the study, outlining its aims, objectives and methodology, was provided to all students enrolled in the two units. This summary stated that the opinions and information provided by participants would be kept strictly confidential and that information used in the final report would be presented in such a way that the source could not be identified. Students were informed they had the right to withdraw from the study at any time. The contact details of the researchers were provided in case students had questions or concerns with the research.

The enrolled students were sent a link to a questionnaire on the SurveyMonkey website in their penultimate week of semester. To minimise the time taken to complete the survey, the majority of questions were categorical. However, many questions also included an optional freeform response to allow students to provide additional information. The content of the online questionnaire is presented as Appendix I.

The survey explored student perception of current services and communication, their experience of flexible delivery mode; and their uptake of and experience of virtual online face-to-face communication. Demographic data were collated to allow for an investigation of their effect on student perception and uptake of services, such as sex, age, country of residence, previous and current studies. In addition to the student survey, the tutor also kept a record throughout semester of the number of students who requested an appointment, the time spent with each student, and issues encountered. SPSS software was used to analyse the frequencies and a thematic analysis was conducted on the qualitative responses.

This study had the approval of Curtin University of Technology Human Research Ethics Committee (HR CIH 5-2008).

\section{Results}

Thirty-one students responded to the questionnaire, of a possible 42 , giving a response rate of $74 \%$. The majority of students surveyed were female, living in Australia and identified as having an Australian background ( 26 of $3 \mathrm{I}$ students). Their ages ranged from 20 to 55 . Eighty-one percent $(\mathrm{N}=25)$ were older than 25 and $48 \%(\mathrm{~N}=15)$ were older than 35 years of age. Eighty-seven percent $(\mathrm{N}=27)$ of the respondents worked in paid employment. Table I provides a summary of the characteristics of the participants. 
Table I: Summary of Student Characteristics

Percentages represent the proportion of students that responded to the survey, of the total number of students enrolled.

\begin{tabular}{|l|l|l|}
\hline Variable & Number of respondents & Number who used CMC \\
\hline Gender & & \\
\hline Male & $\mathrm{N}=5(\mathrm{I} 2 \%)$ & $\mathrm{N}=\mathrm{O}$ \\
\hline Female & $\mathrm{N}=26(62 \%)$ & $\mathrm{N}=4$ \\
\hline Age Groups & & \\
\hline $20-29$ & $\mathrm{~N}=\mathrm{I} 2$ & $\mathrm{~N}=2$ \\
\hline $30-39$ & $\mathrm{~N}=7$ & $\mathrm{~N}=2$ \\
\hline $40-49$ & $\mathrm{~N}=\mathrm{IO}$ & $\mathrm{N}=0$ \\
\hline $50+$ & $\mathrm{N}=2$ & $\mathrm{~N}=\mathrm{O}$ \\
\hline & & \\
\hline Course enrolled & & $\mathrm{N}=3$ \\
\hline International health & $\mathrm{N}=15(\mathrm{IOO} \%)$ & $\mathrm{N}=\mathrm{I}$ \\
\hline Nursing & $\mathrm{N}=\mathrm{I} 6(52 \%)$ & \\
\hline & & $\mathrm{N}=\mathrm{I}$ \\
\hline Country of Residence & & $\mathrm{N}=\mathrm{I}$ \\
\hline Australia & $\mathrm{N}=27$ & $\mathrm{~N}=\mathrm{I}$ \\
\hline Europe & $\mathrm{N}=\mathrm{I}$ & $\mathrm{N}=\mathrm{I}$ \\
\hline Asia & $\mathrm{N}=\mathrm{I}$ & \\
\hline Pacific region & $\mathrm{N}=2$ & $\mathrm{~N}=2$ \\
\hline & & $\mathrm{N}=2$ \\
\hline Employment & $\mathrm{N}=\mathrm{I} 7 \mathrm{IO}$ & \\
\hline Part-Time & & \\
\hline Full- Time & & \\
\hline
\end{tabular}

When asked the reasons for not making use of the additional communication offered, seven students reported their lack of a camera and/or microphone, and three indicated their slow internet speed. Four students ( $13 \%)$, three of whom were aged 47 and above, reported they were uncomfortable with the technology. However, 16 students $(52 \%)$ indicated they had no need for the additional CMC as they were satisfied with the current communication and support services provided by Curtin University and CIH. Three students responded that they did not know that CMC was offered. As only 4 of the $3 \mathrm{I}(13 \%)$ students utilised the CMC, the sample was too small to determine any relationship between students' characteristics such as age or cultural background, and their uptake of the tool offered.

The results of the students' experience with CMC and the potential use of CMC are summarised in Table 2. 
Table 2: Summary of Student Experience

\begin{tabular}{|c|c|c|c|c|c|c|c|}
\hline & $\begin{array}{l}\text { Strongly } \\
\text { Agree }\end{array}$ & Agree & \begin{tabular}{|l|} 
Neither \\
agree \\
nor \\
disagree
\end{tabular} & Disagree & $\begin{array}{l}\text { Strongly } \\
\text { Disagree }\end{array}$ & N/A & \begin{tabular}{|l} 
No \\
response
\end{tabular} \\
\hline $\begin{array}{l}\text { I believe this } \\
\text { communication } \\
\text { affected my learning } \\
\text { experience in a } \\
\text { positive way }\end{array}$ & $3(10 \%)$ & $4(13 \%)$ & $9(29 \%)$ & I $(3 \%)$ & I $(3 \%)$ & $\begin{array}{l}\text { IO } \\
(32 \%)\end{array}$ & $3(10 \%)$ \\
\hline $\begin{array}{l}\text { I believe this } \\
\text { communication } \\
\text { better prepared me } \\
\text { for the assignments }\end{array}$ & $3(10 \%)$ & I $(3 \%)$ & $9(29 \%)$ & $3(10 \%)$ & I $(3 \%)$ & II $(35 \%)$ & $3(10 \%)$ \\
\hline $\begin{array}{l}\text { I believe this } \\
\text { communication } \\
\text { assisted with the } \\
\text { learning outcomes of } \\
\text { the unit }\end{array}$ & $2(6 \%)$ & $3(10 \%)$ & $8(26 \%)$ & $3(10 \%)$ & I $(3 \%)$ & II $(35 \%)$ & $3(10 \%)$ \\
\hline $\begin{array}{l}\text { I would like this } \\
\text { opportunity for } \\
\text { communication made } \\
\text { available in other } \\
\text { units }\end{array}$ & $4(13 \%)$ & I2 (39\%) & $5(16 \%)$ & I (3\%) & I $(3 \%)$ & $5(16 \%)$ & $3(10 \%)$ \\
\hline $\begin{array}{l}\text { I would use additional } \\
\text { modes of } \\
\text { communication, such } \\
\text { as online face-to-face } \\
\text { communication via } \\
\text { Skype or MSN, if } \\
\text { they were available in } \\
\text { other units }\end{array}$ & $3(10 \%)$ & $8(26 \%)$ & $8(26 \%)$ & $4(13 \%)$ & I $(3 \%)$ & $4(13 \%)$ & $3(10 \%)$ \\
\hline
\end{tabular}

Seven students agreed this communication enhanced their learning experience. Although a high proportion of respondents indicated that the questions related to the learning experience and learning outcomes did not apply to them or they responded neither agree nor disagree, there was support for implementation of this communication. Sixteen (52\%) of students indicated they would like CMC such as Skype or MSN to be made available in other units and II (35\%) said they would use such communication if offered.

Students were also given the opportunity to comment on their experience of flexible delivery mode and CMC. The four students who used the communication offered found it to be a positive experience. For example, one student commented: 
"The tutor was very responsive to email communication, which meant that I did most of my communicating with her through that. I used Skype to ask specific questions that were a bit complicated and hard to explain over email." [Student living in Asia, aged 30]

Another student commented: "Great to have verbal contact with tutor and also face to face. I could really understand the information she was giving me". [Student living in the Pacific region, aged 33]

This study intended to trial CMC and provide insight into students' experience of their course, and many of the students commented favourably. Their positive experience was best exemplified by the comment made by a student living in Europe:

"I feel that during my distance education study with Curtin that I have had more contact with my tutors than I did during my undergraduate degree that I did internally (at a different university). I have found that Curtin has offered good communication methods (email, telephone and Skype) and I am very happy with the way my course is provided." [Post graduate student in International Health]

The tutor estimated her time managing both units to be approximately 50 hours for the semester, not including time spent marking assignments. This comprised a welcome email, and telephone and email communication with students throughout the semester. Her time spent implementing Skype and MSN communication totalled three hours over the semester, indicating that the addition of this CMC did not increase her teaching workload significantly. The tutor also indicated that when addressing complex questions she preferred MSN/Skype (if available to students) or telephone communication, as she found email more time consuming.

\section{Discussion}

This study provided an exemplar case study of the practicality and effectiveness of offering virtual online face-to-face communication to post-graduate students studying via flexible delivery mode. Four ( $13 \%)$ of the 42 enrolled students used the CMC offered, and $16(52 \%)$ indicated they would like to see similar communication offered in other units, and for Curtin University and $\mathrm{CIH}$ to continue to provide quality support services. The following discussion is not intended to be definitive, as the limitations of the sample size and sampling must be taken into account. However, the results can be considered indicative of the population of post-graduate Health Sciences students

The tutor considers the advantages of offering such communication, and her own and the students' experience of the communication outweigh the minimal additional time required to implement the tool. Some of the barriers to the implementation of this tool in other units could be resolved with increased support around its uptake; some students indicated they would use CMC with assistance. Despite repeated emails and announcements on WebCT, there were students who did not use CMC as they did not know it was available, so wider promotion would be necessary. 
Similar studies done on undergraduate students have had a higher level of uptake, so it may be that older post-graduate students are less inclined to adopt new technology. None of the students who accessed CMC were older than 35 , so age may have been a confounding variable. The current group of undergraduate students is more inclined to trial, even seek new technologies and alternate methods of communication, and as they move into postgraduate study, they may expect a variety of forms of CMC with their tutor, creating a greater demand for tools such as Skype.

Internet speed and not having a camera or microphone were also reported as reasons for students not utilising the service. Consideration should be given to groups of students who will not be supported by this communication. The benefits of offering CMC are reduced if remote and/or technologically limited locations further disadvantage students, leading to increased feelings of isolation, and a diminished, rather than enhanced learning experience (Bates, 2005).

Although some students gave their lack of equipment as reason for not using CMC, I6 (52\%) said they had no need for this form of communication. This may have been due to their having previously completed a tertiary qualification, or because they already felt well supported by the university. As the majority of students who did not access CMC live in Australia, and three of the four students who accessed the service live overseas, our findings support those of Ludwig-Hardman and Dunlap (2003), who found isolation influences the level of support desired by students. The cost of a local call within Australia may be minimal and the convenience of picking up the phone to contact the tutor may explain why there was less uptake of this CMC by students who live in Australia. In contrast, the cost of an international call may be prohibitive and the use of Skype and MSN, which does not incur additional financial cost, may be a more attractive option of communication for students who live overseas.

Face-to-face communication has the advantage of both verbal and nonverbal signals, providing multiple opportunities for clarification of meaning; whereas forms of CMC such as email do not provide the same set of signals (DeVito, 2008). Several students commented that CMC was useful for questions that were not suited to email. Collis and Moonen (2007) argue blended courses are best, with face-to-face contact provided at least once; they assert seeing and hearing educators facilitates students' interpretation of subsequent written feedback. Real time or synchronous CMC is important for interaction between educators and non campus-based students (Shih, Hung, Ma \& Jin, 2007). Although only four students used the communication, seven indicated it had positively affected their learning experience, suggesting that the use and availability of a service can improve the students' experience.

The study aimed to assess students' uptake, perceptions and experience of CMC. As only a few students made use of CMC, this could be perceived as an unnecessary service to offer, and confirmation that Curtin University and CIH are meeting the needs of students. However, CMC's practicality and effectiveness as a communication tool are reflected in the positive ex- 
perience of the tutor and students who used it. It may be that the necessity of such a tool is of less importance than its potential to enhance the learning experience of students. Although this study is unable to provide evidence that this form of CMC will improve student learning, it has demonstrated that students have positive learning experiences when well supported and provided with adequate opportunities for communication with their tutor.

Although many students did not require CMC, some students may have been more inclined to use it had they owned the necessary equipment. Further implementation might involve requiring students to purchase a headset, as is the case for students studying a Graduate Diploma of Midwifery, which has a blended teaching approach (Morrow, Phillips \& Bethune, 2007). A couple of the students gave their reason for not using CMC as their uneasiness with the technology, so a manual that explains step-by-step how to use Skype, MSN or similar software should be provided to students to facilitate their use.

Future studies could target the students' response to different tutors. Some tutors may be less equipped to ensure student experience of CMC is positive. Academic staff are often encouraged, rather than supported, to implement CMC (Barber \& Wilkinson, 2005). This study focused on the student experience of CMC, but further research could explore the impact of staff development on both tutors' and students' experience of CMC.

\section{Conclusion}

This case exemplar indicates that CMC can be practically and effectively implemented to improve the level of engagement between a tutor and postgraduate students. In this study, few students chose to utilise the CMC but those who did, had a positive experience. Students indicated they would use this service if they needed to and they considered it potentially useful to enhance their learning experience. 


\section{References}

Barber, W. \& Wilkinson, M. (2005). The change in academic skill base required for the transition from face-to-face teaching to blended delivery. Paper presented at ODLAA Breaking down Boundaries, ${ }_{1} 7^{\text {th }}$ Biennial Conference of the Open and Distance Learning Association of Australia, 9-II November 2005, Adelaide, South Australia. Paper available from http://www.odlaa.org/events/2005conf/nonref/odlaa2005BarberWilkinsonAbstract.pdf

Bates, A.W. (2005). Technology, E-learning and Distance Education. London: Routledge.

Berge, Z.L. (2007). Motivate and Manage: Key Activities of Online Instructors. In J.M. Spector (Ed.), Finding your Online Voice: Stories Told by Experienced Online Educators (pp.73-82). New Jersey: Lawrence Erlbaum Associates.

Bonk, C.J. \& King, K.S. (I998). Electronic Collaborators: Learner Centered technologies for Literacy, Apprenticeship and Discourse. Mahwah, New Jersey: Lawrence Erlbaum Associates.

Bridgland, A.C. \& Blanchard, P. (200I). Flexible delivery/ flexible learning: ... does it make a difference?. Australian Academic and Research Libraries, 32(3), I77-I9I.

CASS (2008). Curtin Annual Student Satisfaction Survey (CASS) - Report 2007. Published February 2008. Retrieved June I9, 2008, from http://planning.curtin.edu.au/local/docs/CASS_report_2007.pdf

Collis, B. \& Moonen, J. (2007). The Contributing Student: Philosophy, Technology and Strategy. In J.M. Spector (Ed.), Finding your Online Voice: Stories Told by Experienced Online Educators (pp.19-32). New Jersey: Lawrence Erlbaum Associates.

DeVito, J. A. (2008). Human Communication: The Basic Course (II ${ }^{\text {th }}$ ed.). New York: Allyn \& Bacon.

Elison-Bowers P., Snelson C., Casa de Calvo, M. \& Thompson, H. (2008). Health science students and their learning environment: a comparison of perceptions of on-site, remote-site, and traditional classroom students [online]. Perspectives in health information management / AHIMA, American Health Information Management Association, $5(2)$.

Ellison, N.B., Steinfield, C. \& Lampe, C. (2007). The benefits of Facebook "friends": Social capital and college students' use of online social network sites [online]. Fournal of Computer-Mediated Communication, I2(4), article I. Retrieved July 3, 2008, from http://jcmc.indiana.edu/volı2/issue 4/ellison.html 
Frank, J., Toland, J. \& Schenk, K. (2004). The Effect of Culture on Email Use: Implications for Distance Learning. In C. Howard, K. Schenk \& R. Discenza (Eds.), Distance Learning and University Effectiveness: Changing Educational Paradigms for Online Learning. Chapter XI (pp. 213-233). London: Information Science Publishing.

Hiltz, S. \& Johnson, K. (I990). User Satisfaction with Computer-Mediated Communication Systems. Management Science, 36(6), 739-764.

Hiltz, S. \& Turoff, M. (1985). Structuring Computer-Mediated Communication Systems to avoid information overload. Communications of the Association for Computing Machinery 28(7), 680-689.

Hoskins, S.L., \& van Hoof, J.C. (2005). Motivation and ability: which students use online learning and what influence does it have on their achievement? British fournal of Educational Technology, 36(2), I77-I92.

Kember, D. (2007). Reconsidering open and distance learning in the Developing World-Meeting students' learning needs. New York: Routledge.

Khan, B. (2005). Managing E-Learning: Design, Delivery, Implementation and Evaluation. London: Information Sciences Publishing.

Leach, K. \& Walker, S. (200o). Internet Based Distance Education: Barriers, Models, and New Research. In Proceedings of WebNet World Conference on the WW and Internet (pp.903-905). Chesapeake, Virginia: Association for the Advancement of Computing Education.

Ludwig-Hardman, S. \& Dunlap, J. C. (2003). Learner Support Services for Online Students: Scaffolding for success. International Review of Research in Open and Distance Learning, 4(I), I97-2II.

McKenzie, O., Christensen, E.L. \& Rigby, P.H. (I968). Correspondence instruction in the United States. New York: McGraw Hill.

Morrow, J., Phillips, D. \& Bethune, E. (2007). Teaching and learning: flexible modes and technology applications. British fournal of Midwifery, ${ }_{5}(7), 445-448$.

Muirhead, B. \& Betz, M. (2005). Transitional Developments in Online Courses and Programs: Theory and Practice. Educational Techno$\log y$ \& Society, 8(2), I-6.

Nichols, M. \& Gardner, N. (2002). Evaluating flexible delivery across a Tertiary Institution. Open Learning, I7(I), II-22.

Richardson, J.T.E. \& Price, L. (2003). Approaches to studying and perceptions of academic quality in electronically delivered courses. British fournal of Educational Technology, 34(I), 45-56.

Shih, T.K., Hung, J.C., Ma, J. \& Jin, Q. (2007). A Survey of Distance Education Challenges and Technologies. In T.K. Shih and J.C. Hung (Eds.), Future Directions in Distance Learning and Communication Technologies (pp.I -25). London: Information Science Publishing.

Simonson, M., Smaldino, S., Albright, M. \& Zvacek, S. (2000). Teaching and learning at a distance-Foundations of distance education. New Jersey: Prentice-Hall, Inc. 
Simpson, O. (2000). Open and Distance Learning Series. Supporting Students in Open and Distance Learning. London: Kogan Page Limited.

Smith, P.J., \& Smith, S.N. (1999). Differences between Chinese and Australian students: Some implications for distance educators. Distance Education, 20 (I), 64-80.

Taylor, J.C. (I995). Distance education technologies: The fourth generation. Australian fournal of Educational Technology, II(2), I-7.

Taylor, J.C. (2000). New Millennium Distance Education. In V. Reddy and S. Manjulika (Eds.), The World of Open and Distance Learning (pp. 475-48o). India: Viva Books Private Ltd.

Yorke, M., Bernett, G., Evanson, P., Haines, C., Jenkins, D., Knight, P., Scurry, D., Stowell, M. \& Woolf, H. (2005). Mining institutional datasets to support policy making and implementation. Fournal of Higher Education Policy and Management, 27(2), 285-298.

Zepke, N., Leach, L., Prebble, T., Campbell, A., Coltman, D., Dewart, B., Gibson, M., Henderson, J., Leadbeater, J., Purnell, S., Rowan, L., Solomon, N. \& Wilson, S. (2005). Improving tertiary student outcomes in the first year of study. Wellington, New Zealand: Teaching and Learning Research Initiative. 


\section{Appendix I: Questionnaire}

This research project aims to investigate the learning experience of students studying at Curtin University through flexible delivery mode. All students enrolled in Research and Evaluation in International Health and Topics in International Health are being asked to complete a short questionnaire, prior to the conclusion of Semester Two. The survey should take no more than ten minutes to complete.

Any information will be treated in the strictest confidence. No identifying data will be included in the final report unless the respondent has given permission. All collected information will be carefully secured at all times by the researcher. Raw data will only be accessed by Kate Thomson and research assistants who may be involved in the data analysis. The tutor and unit coordinator will not have access to this data.

http://www.surveymonkey.com/MySurvey_EditPage.aspx?sm=zU4OfsFMFOsRxjoNeW 4IANpD2JKMQxpARrnnDc9UIZxqY9 ${ }_{9}{ }_{7} \% 2{ }_{2} \% 2 b-$ GHinCQkeooaKRd8V8pPdFSZOSpWBIugc4twbhx2xVzg46p6SqxOjG$\mathrm{xz} \% 2 \mathrm{bQ} \% 3 \mathrm{~d} \& \mathrm{~TB} \_$iframe$=$true $\&$ height $=475 \&$ width $=650$

*. Which unit(s) are you enrolled in? ${ }^{\mathrm{I}}$

- Research and Evaluation in International Health

- Topics in International Health

- Both REIH and Topics

*2. Are you?

- Male

- Female

*3. How old are you? ${ }^{2}$

*4. Are you an International Student?

- Yes

- No

- I do not know

*5. What culture or ethnicity do you identify with? For example, Asian-Indian or Chinese-Australian.

I.Questions marked with an asterisk were compulsory

2.Question 3 allowed a freeform response 
*6. Where do you live?

- Australia

- Asia

- Europe

- America

- Africa

- Other (please specify)

${ }^{*}$. What is the highest level of education you have completed? ${ }^{3}$

*8. In which degree are you enrolled?

*9. Are you currently employed?

* Io. Would you consider this?

- Full-time

- Part-time

- Casual

- Voluntary

- Other (please specify)

${ }^{*}$ II. What is your main occupation? ${ }^{4}$

*I2. How do you usually access the internet?

- Personal-I have a connection to the internet at home

- Business-I use the computer where I work to access the internet

- Casual-I use Internet cafes, or borrow friends' computers to access the internet

- Other (please specify)

${ }^{*} \mathrm{I} 3$. What kind of internet connection is this?

- $28.8 \mathrm{Kbps}$ modem

- $56 \mathrm{Kbps}$ modem

- IDSN

- Cable modem

- DSL

- Tr or better

- I do not know

- Other (please specify)

3.Questions 7 and 8 required a response from a drop down menu 4.Question II allowed a freeform response 
*I4. Did you use the Computer Mediated Communication (ie Skype or MSN) offered in this unit?

- Yes

- No

${ }^{*}$ I5 A. Please tell us why you chose to use this form of communication; was it to ask about

- Assignment I

- Assignment 2

- The take home exam

- The readings

- The unit outline

- Referencing

- An extension

- Other (please specify)

${ }^{*}{ }_{5} \mathrm{~B}$. Please explain why you chose not to use this form of communication (you can select as many options as are appropriate for you)

- There is a time difference

- I don't have a camera

- I don't have a microphone

- My internet is too slow

- I was uncomfortable with the technology

- I didn't need to

- Other (please specify)

${ }^{*}$ I7. Please indicate whether you agree or disagree with the following set of statement ${ }^{5}$ :

- I believe this communication affected my learning experience in a positive way

- I believe this communication better prepared me for the assignments

- I believe this communication assisted with the learning outcomes of the unit

- I would like this opportunity for communication made available in other units

- I would use additional modes of communication, such as online face-toface communication via Skype or MSN, if they were available in other units

5. These questions required a response using Likert scales, from Strongly Agree to Strongly Disagree, with an N/A option. See Table 2 for detail. 
http://www.surveymonkey.com/QuestionBuilderFrame.aspx?sm=zU4OfsFMFOsRxjoNeW 4IANpD2JKMQxpARrnnDc9UIZw5eHdGı\%2bgrKvtODqHLofoay9sSBOG\%2f\%2bwbRWoEhyvbMdVXjnetfyp454FrHXhosOa8\%3d\&TB_iframe=true \&height $=*$ \&width $=725$

I8. Please use the space below to comment on the aspects of this communication that you enjoyed and have helped you learn ${ }^{6}$

I9. Please use the space below to recommend improvements to this form of communication

20. Please use the space below for recommendations or suggestions for improving any aspect of your learning experience at Curtin University

2I. Are there any other comments you would like to make?

javascript:void(null);http://www.surveymonkey.com/QuestionBuilderFrame.aspx?sm=zU4 OfsFMFOsRxjoNeW 4IANpD2JKMQxpARrnnDc9UIZyQEauknecQ6hN7xVXBSAjoOPZH6w7ltGL\%2b89kCZZIxsmdoQi6\%2fov5nraoS9\%2fzbOipmuqOEnriqh9QsNL84ImfVpht3bJr8MLKAKDKmxci6rwNZ 7 sQRbyH2\%2b9f\%2foray998\%3d\& TB_iframe=true\&height $=*$ \&width=70ohttp://www.surveymonkey.com/ MySurvey_EditPage.aspx?sm=zU4OfsFMFOsRxjoNeW4IANpD2JKMQxpARrnnDcøUIZyQWyQ\%2bkfg6bttLAmjLdsZxYEQWSczEmVDv$\% 2 f y \% 2 f p E 2 w N 6 o g 3 p B a r E N Q V r e i Q h I R 8 Y 5 M \% 3 d \& T B \_i f r a m e=t r u e-$ \&height $=475$ \&width $=650$

Thank you

Thank you for taking the time to complete this survey. When the research has been completed, you will be provided with a one page summary of results.

If you have any questions or concerns, please do not hesitate to contact those listed on the information sheet.

javascript:void(null);http://www.surveymonkey.com/QuestionBuilder-

Frame.aspx?sm=zU4 OfsFMFOsRxjoNeW 4IANpD2JKMQxpARrnnDc9UIZxPGFWUBOSscUCzSbAf2HZIVJiTu2VTDpE5bgg7lfwxKiDLQOmUTejqXk4B\%2bTF8IYYaRtOwZpw9XDQ\%2fgEC\%2fe7QKy\%2f 3 Rq7yHKm45PsoRogMBEEUwyriQgiNp68k4i\%2foJPEc\%3d\&TB_iframe=true\&height=*\&width=70ohttp://www.surveymonkey.com/MySurvey_Edit

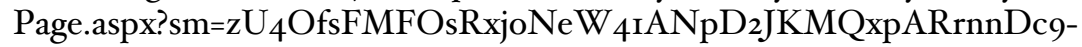
UIZw4IuxCZAaGtk7\%2flKZ6aHIcYytlS2cH3 TvNjySYmxbJ5fidhNCL6qnX\%2fc\%3d\&TB_iframe $=$ true $\&$ height $=475 \&$ width $=650$

6.Questions I8-2I allowed freeform responses 